\title{
Oral health in older people: time for action
}

\author{
A. E. Kossioni ${ }^{1}$ (D) S. Maggi ${ }^{2} \cdot$ F. Müller ${ }^{3} \cdot$ M. Petrovic ${ }^{4}$
}

Received: 15 October 2017 / Accepted: 23 October 2017 / Published online: 22 January 2018

(C) European Geriatric Medicine Society 2018

The common Task and Finish (T\&F) group on Gerodontology of the European College of Gerodontology (ECG) and the European Geriatric Medicine Society (EUGMS) recently published an expert opinion document on oral health assessment and promotion in older people by nondental care providers [1]. That document provides geriatric oral health policy recommendations, with particular focus on frail and care-dependent older people. The need for these recommendations was prompted by the poor oral health in frail older people, facing multiple barriers to oral care, urging the need for interprofessional educational collaboration and practice. Target audience for these recommendations consists of health policy makers, but also all health care professionals treating older people, such as geriatricians, internists, general medical practitioners, dentists, nurses and nursing assistants, physical therapists, pharmacists, medical assistants, physiotherapists, occupational therapists, dieticians, and others.

Common oral diseases in old age are tooth loss, denturerelated conditions, poor oral cleanliness, caries, periodontal disease, hyposalivation, oral precancerous conditions, and oral cancer [2-5]. These conditions may cause pain, local and systemic infection, chewing and swallowing problems, aesthetic problems, and occasionally increased mortality. In addition, bad breath and a poor dental appearance can increase social isolation. Oral infections and periodontal disease have been closely associated with general health

A. E. Kossioni

akossion@dent.uoa.gr

1 Division of Gerodontology, Dental School, National and Kapodistrian University of Athens, Thivon 2 Goudi, 11527 Athens, Greece

2 Aging Branch, CNR Neuroscience Institute, Via Giustiniani 2, 35127 Padua, Italy

3 Department of Gerodontology and Removable Prosthodontics, Dental School, University of Geneva, CMU, 1 rue Michel-Servet, 1211 Geneva 4, Switzerland

4 Department of Internal Medicine (Geriatrics), Faculty of Medicine and Health Sciences, Ghent University, De Pintelaan 185, 9000 Ghent, Belgium such as cardiovascular disease, diabetes mellitus, and lower respiratory tack infections, while tooth loss may have negative effects on diet and nutrition [2-8]. At the same time, oral disease can be prevented by daily oral hygiene, appropriate lifestyle interventions (i.e. healthy diet and smoking cessation), and regular professional oral health care and follow-up [9].

Despite the high prevalence of oral problems in old age, dental attendance by frail older people is low. Therefore, the role of non-dental health care providers in assessing and promoting oral health becomes very important [10]. They have the opportunity to assess oral problems, recommend or perform basic preventive measures to patients and refer to the dentist or dental hygienist, when appropriate. However, this rarely happens due to lack of necessary knowledge, skills, and attitudes towards oral health promotion or lack of appropriate policies and legislations.

The T\&F group on Gerodontology has identified three major sources of oral health barriers in old age: (a) personrelated issues, such as physical illness, reduced mobility, cognitive impairment, care dependency, low socioeconomic background, living in rural areas or in residential care, financial problems etc. [3-5, 11-13], (b) lack of professional support, including limited training of nondental health care providers in oral health $[4,13,14]$, and (c) lack of effective oral health policies, including poor legislations, policies and regulations on dental care in the community and in institutional care, and limited public dental care coverage combined with the high cost of dental treatment.

Three areas requiring urgent interventions have been proposed: educational action plans, health policy action plans, and citizens' empowerment and involvement.

First, educational action plans should involve both dental and non-dental health care providers, offering interprofessional training opportunities, hands-on training and improvement of attitudes towards oral health promotion. Dental professionals require more training in oral care for frail and care-dependent older people, while non-dental health care professionals should be educated in oral health assessment and promotion at the undergraduate, 
postgraduate, and specialty level. A list of learning objectives has been identified including recognizing oral health as part of multi-morbidity, reflecting current medication regimens towards their impact on oral health, performing an initial assessment of the oral health status, demonstrating oral hygiene measures to the older adults and the carers, developing strategies to overcome barriers to oral health maintenance and access to dental care, deciding when to refer to the dentist, and supporting collaborative practice.

Second, the recommendations include a list of health policy action plans, prioritizing the integration of oral health into the general health assessment, the implementation of preventive oral health care in routine medical care schemes and the inclusion of oral care into public health care, as financial restrictions are significant barriers to dental care. Emphasis is also placed into domiciliary care and promotion of oral health prevention campaigns for the public.

A very important part of the recommendations is related to the development of policies and protocols on oral health promotion in institutional care settings, including oral health assessment upon entry, provision of daily oral hygiene, training the carers in oral health provision to residents, provision of a healthy diet, ensuring access to emergency and routine dental care, and provision of regular oral screenings for residents using appropriate validated tools.

Last but not least, the empowerment and involvement of citizens in actions related to oral care for the older adults was highly emphasised in the final part of the recommendations. Citizens may guide decision-makers in enforcing legislations for oral health promotion and coverage by state or social security, as well as strategies for promoting oral health literacy.

These recommendations, valid in Europe, may also prove beneficial to other countries facing similar sociomedical problems, particularly in the Americas, Asia, and Australia, and may be used as advocacy tools by national and international authorities to develop appropriate policies and legislations.

Acknowledgements The authors would like to thank all members of the T\&F group on Gerodontology that co-authored the expert opinion document (in alphabetical order): Dr Justyna Hajto-Bryk, Dr Gerry McKenna, Professor Regina Elisabeth Roller-Wirnberger, Professor Martin Schimmel, Professor Marija Tamulaitienè, and Professor Jacques Vanobbergen.

Funding None.

\section{Compliance with ethical standards}

Conflict of interest The authors declare that they have no conflict of interest.
Ethical approval This article does not contain any studies with human participants performed by any of the authors.

Informed consent Informed consent is not required.

\section{References}

1. Kossioni A, Hajto-Bryk J, Maggi S, McKenna G, Petrovic M, Roller-Wirnberger RE et al (2017) An expert opinion from the ECG and the EUGMS: European policy recommendations on oral health in older adults. J Am Geriatr Soc. https://doi.org/10.1111/ jgs. 15191

2. Petersen PE, Yamamoto T (2005) Improving the oral health of older people: the approach of the WHO Global Oral Health Programme. Community Dent Oral Epidemiol 33:81-92

3. Müller F, Schimmel M (2010) Tooth loss and dental prostheses in the oldest old. Eur Geriatr Med 1:239-243

4. van der Putten G-J, De Visschere L, van der Maarel-Wierink C, Vanobbergen J, Schols J (2013) The importance of oral health in (frail) elderly people — a review. Eur Geriatr Med 4:339-344

5. Petersen PE, Kandelman D, Arpin S, Ogawa H (2010) Global oral health of older people - call for public health action. Community Dent Health 27:257-268

6. Awano S, Ansai T, Takata Y, Soh I, Akifusa S, Hamasaki T et al (2008) Oral health and mortality risk from pneumonia in the elderly. J Dent Res 87:334-339

7. Chapple IL, Genco R, working group 2 of the joint EFP/AAP workshop (2013) Diabetes and periodontal diseases: consensus report of the joint EFP/AAP workshop on periodontitis and systemic diseases. J Periodontol 84(4 Suppl):106-112

8. Ott A, Veronese N, Damulevičienė G, Kasiukiewicz A, Tsiantouli E (2017) Oral health and dysphagia in the older population: report of the 2nd EICA-ESSD-EUGMS train the trainers course. Eur Geriatr Med 8:191-195

9. Tonetti M, Bottenberg P, Conrads G, Eickholz P, Heasman P, Huysmans M-C et al (2017) Dental caries and periodontal diseases in the ageing population: call to action to protect and enhance oral health and well-being as an essential component of healthy ageing - Consensus report of group 4 of the joint EFP/ ORCA workshop on the boundaries between caries and periodontal diseases. J Clin Periodontol 44(Suppl):S135-S144

10. Hummel J, Phillips KE, Holt B, Hayes C (2015) Oral health: an essential component of primary care. White paper, June 2015. http://www.niioh.org/sites/default/files/Oral_Health_white_paper_ final.pdf. Accessed 19 Oct 2017

11. Strayer MS (1995) Perceived barriers to oral health care among the homebound. Spec Care Dent 15:113-118

12. Borreani E, Wright D, Scambler S, Gallagher JE (2008) Minimising barriers to dental care in older people. BMC Oral Health 8:7. https://doi.org/10.1186/1472-6831-8-7

13. Kossioni AE (2012) Is Europe prepared to meet the oral health needs of older people? Gerodontology 29:e1230-e1240

14. Andersson K, Furhoff AK, Nordenram G, Wårdh I (2007) 'Oral health is not my department'. Perceptions of elderly patients' oral health by general medical practitioners in primary health care centres: a qualitative interview study. Scand J Caring Sci 21:126-133 